\title{
Treatment of upper urinary tract stones with extracorporeal shock wave lithotripsy (ESWL) Sonolith vision
}

\author{
Kogenta Nakamura1*, Motoi Tobiume1, Masahiro Narushima², Takahiko Yoshizawa', Genya Nishikawa1, \\ Yoshiharu Kato ${ }^{1}$, Remi Katsuda ${ }^{1}$, Kenji Zennami ${ }^{1}$, Shigeyuki Aoki ${ }^{1}$, Yoshiaki Yamada', Nobuaki Honda ${ }^{1}$ and \\ Makoto Sumitomo'
}

\begin{abstract}
Background: The aim was to retrospectively assess the results of treatment of upper urinary tract stones with the Sonolith vision manufactured by EDAP, and purchased in 2004.

Methods: The subjects were 226 Japanese patients who underwent extracorporeal shock wave lithotripsy (ESWL) alone as an initial treatment and could be followed up for at least 3 months, selected from 277 candidate patients who underwent this therapy between 2004 and 2006. Treatment effect was evaluated by kidney, ureter, and bladder X-ray or renal ultrasonography at 1 and 3 months after treatment. A stone-free status or status of stone fragmentation to $4 \mathrm{~mm}$ or smaller was considered to indicate effective treatment.

Results: At 3 months after treatment, the stone-free rate was $69.4 \%$ and the efficacy rate was $77.4 \%$ for renal stones, while these rates were 91.5 and $93.3 \%$, respectively for ureteral stones. Assessment of treatment effect classified by the location of stones revealed a stone-free rate of $94.6 \%$ and an efficacy rate of $94.6 \%$ for lower ureteral stones (4.0 mm or smaller, 1 subject; 4.1-10.0 mm, 31 subjects; 10.1-20.0 mm, 5 subjects: number of treatment sessions, 1 or 2 sessions [mean: 1.03 sessions]). Complications of this therapy included renal subcapsular hematoma and pyelonephritis in 1 case each.

Conclusions: ESWL with the Sonolith vision manufactured by EDAP produced a treatment effect equivalent to those achieved with other models of ESWL equipment. ESWL seems to be an effective first-line treatment also in patients who have lower ureteral stones $10 \mathrm{~mm}$ or larger but do not wish to undergo TUL, if measures such as suitable positioning of the patient during treatment are taken.
\end{abstract}

\section{Background}

Extracorporeal shock wave lithotripsy (ESWL) was introduced in clinical practice by Chaussy et al. in the $1980 \mathrm{~s}$ [1]. Its usefulness is widely recognized, and it has become the most common treatment for upper urinary tract stones. ESWL has been performed more frequently than TUL for stone treatment in Japan compared with that in Europe and the United States (2008 General Meeting, Seminar of the Japanese Urological Association), which may be largely attributable to its simplicity

\footnotetext{
* Correspondence: kogenaka@aichi-med-u.ac.jp

'Department of Urology, Aichi Medical University School of Medicine Nagakute, Aichi 480-1195, Japan

Full list of author information is available at the end of the article
}

and/or the National Health Insurance System in Japan. Our hospital introduced the Sonolith vision (manufactured by EDAP) in March 2004 in place of the old equipment, and has been performing ESWL on patients with upper urinary tract stones. Here we report the favorable results of treatment of lower ureteral stones in cases where lithotripsy was difficult, which were achieved by putting the patient in a suitable position.

\section{Methods}

The present study was reviewed and approved by the Ethics Committee of Aichi Medical University School of Medicine (No. 11-015). The subjects were 226 Japanese patients who underwent ESWL alone and could be

\section{Ciomed Central}


followed up for at least 3 months, selected from 277 candidate patients who underwent this therapy as the initial treatment between March 1, 2004 and December 31, 2006. The subjects included 169 male and 57 female aged from 17 to 86 years (mean: 50.5 years). The stones were on the left side in 128 subjects and on the right side in 98. The locations and sizes of the stones are shown in Table 1.

Treatment was performed during a hospital stay of three days and two nights, and the subjects were only fasted before operation. Preoperative medication included diclofenac suppository, Atarax-P, atropine sulfate (i.m.), and glycerin enema $(60 \mathrm{~mL})$. When subjects complained of severe pain during operation, pentazocine (i.m.) was additionally administered. Renal stones were treated at a maximum energy level of $80 \%$, while ureteral stones were treated at a level of $100 \%$. Both renal and ureteral stones were treated with up to 3000 shock waves. Treatment effect was evaluated by kidney, ureter, and bladder (KUB) X-ray or intravenous pyelography at 1 and 3 months after operation, and was classified as stone-free status (absence of residual stones), effective (presence of residual stones $4 \mathrm{~mm}$ or smaller), inadequate (status other than the above), or ineffective (no stone fragmentation even after 2 treatment sessions of ESWL).

Treatment was completed if an effective or better response was demonstrated by KUB on the day after the operation. If stone fragmentation was found to be inadequate, a second ESWL session was performed after about 1 to 4 weeks. If any stone fragmentation was achieved, third and subsequent ESWL sessions were performed. Subjects with an inadequate or no response (ineffective) to ESWL underwent transurethral ureterolithotripsy (TUL) or percutaneous nephrolithotripsy (PNL). Subjects with urinary tract infection or with stones $20 \mathrm{~mm}$ or larger underwent placement of a double-J stent. During the procedure, subjects with renal or upper ureteral stones were placed in the ipsilateral supine position, those with middle ureteral stones in the ipsilateral prone position, and those with lower ureteral

Table 1 Location and size of stones

\begin{tabular}{|c|c|c|c|c|c|}
\hline & $\begin{array}{c}\leq 4.0 \\
\mathrm{~mm}\end{array}$ & $\begin{array}{c}4.1-10.0 \\
\mathrm{~mm}\end{array}$ & $\begin{array}{c}10.1-20.0 \\
\mathrm{~mm}\end{array}$ & $\begin{array}{c}\geq 20.1 \\
\mathrm{~mm}\end{array}$ & $\begin{array}{c}\text { Total } \\
(\mathrm{n})\end{array}$ \\
\hline Middle renal & & 5 & 36 & 11 & 52 \\
\hline Lower renal & & 2 & 7 & 1 & 10 \\
\hline $\begin{array}{l}\text { Upper } \\
\text { ureteral }\end{array}$ & & 77 & 35 & 1 & 113 \\
\hline $\begin{array}{l}\text { Middle } \\
\text { ureteral }\end{array}$ & & 11 & 3 & & 14 \\
\hline $\begin{array}{l}\text { Lower } \\
\text { ureteral }\end{array}$ & 1 & 31 & 5 & & 37 \\
\hline Total (n) & 1 & 126 & 86 & 13 & 226 \\
\hline
\end{tabular}

stones in the contralateral prone position (Figure 1). Subjects with X-ray-negative stones underwent intravenous pyelography (IVP) and ureteral catheter insertion in combination with ESWL.

\section{Results}

Of the 226 cases, 30 cases underwent placement of a ureteral stent and 14 cases underwent IVP. When the stones were classified by location, middle renal stones were the most frequent (52 cases) among subjects with renal stones, while upper ureteral stones (113 cases) were the most frequent among subjects with ureteral stones. When the stones were classified by size, those $10.1-20.0 \mathrm{~mm}$ were the most frequent (43 cases) of renal stones, while those $4.1-10.0 \mathrm{~mm}$ were the most frequent (119 cases) of ureteral stones. One to 10 treatment sessions (mean: 1.62 sessions) were performed. Renal stones were treated with a mean of 1.8 sessions, of which middle renal stones of $20.1 \mathrm{~mm}$ or larger were treated with the largest number of sessions (mean: 3.9 sessions). Ureteral stones were treated with a mean of 1.44 sessions, of which middle ureteral stones of 10.1 $20.0 \mathrm{~mm}$ or larger were treated with the largest number of sessions (mean: 3.6 sessions) (Table 2). One month after operation, the stone-free rate was $48.4 \%$ and the efficacy rate was $64.5 \%$ for renal stones, while these rates were 70.7 and $80.5 \%$, respectively for ureteral stones. Three months after operation, the stone-free rate was $69.4 \%$ and the efficacy rate was $77.4 \%$ for renal stones, while these rates were 91.5 and $93.3 \%$, respectively for ureteral stones. When the treatment effect was analyzed by the location of stones, a stone-free rate of $94.6 \%$ and an efficacy rate of $94.6 \%$ were achieved in subjects with lower ureteral stones $(\leq 4.0 \mathrm{~mm}, 1$ subject; $4.1-10.0 \mathrm{~mm}, 31$ subjects; $10.1-20.0 \mathrm{~mm}, 5$ subjects) with one or two ESWL treatment sessions (mean: 1.03 sessions) at three months after operation (Table 3). All five subjects with stones $10 \mathrm{~mm}$ or larger achieved a complete stone-free status.

Fourteen subjects with X-ray-negative stones underwent intravenous pyelography (IVP) and ureteral catheter insertion in combination with ESWL. These patients had a stone-free status with only ESWL therapy.

Of the 25 cases in whom ESWL was ineffective, 8 cases were confirmed to be stone free three or more months after operation, while 7 cases with residual stones were followed up because hydronephrosis improved. Of the subjects with upper ureteral stones in whom ESWL was ineffective, 7 cases underwent TUL and 2 cases underwent PNL. One case with concomitant ureteral stenosis underwent holmium laser incision following stone fragmentation with TUL.

The chemical composition of stones could be determined in 128 cases. Calcium oxalate stones were the 


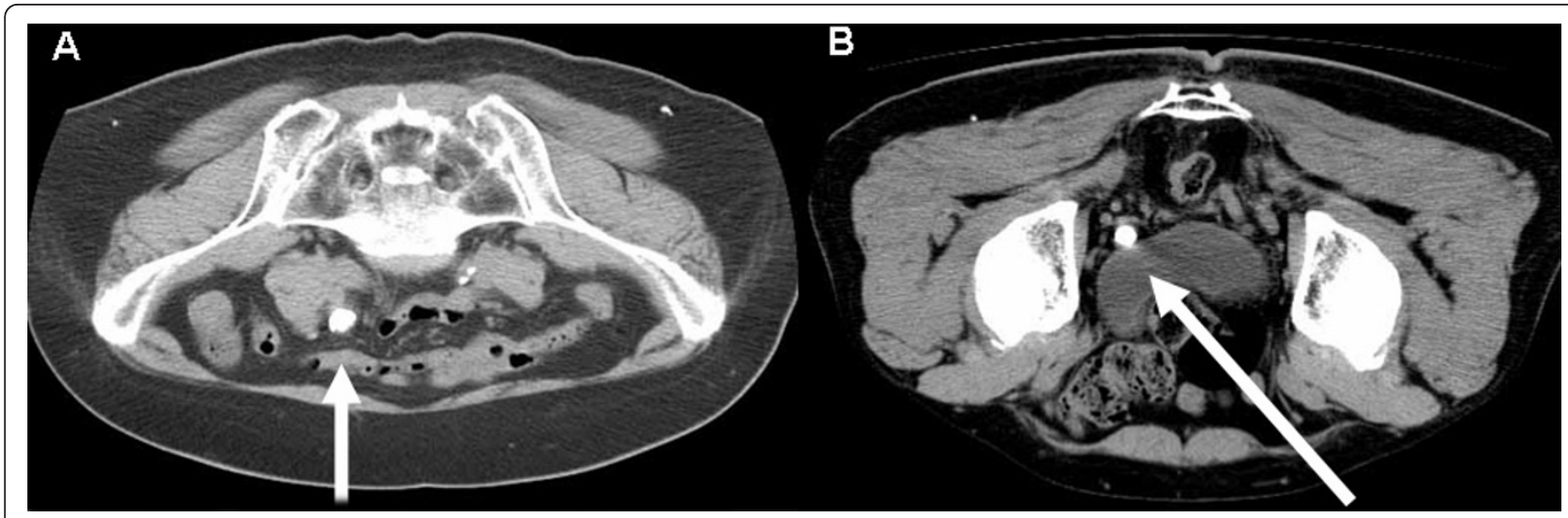

Figure 1 A) ESWL approaches to middle ureteral stones. (Ipsilateral prone position). B) ESWL approaches to lower ureteral stones. (Contralateral prone position)

most frequent (68 cases), followed by mixed calcium oxalate and calcium phosphate stones (49 cases), and stones containing calcium were present in 126 cases.

All subjects experienced postoperative gross hematuria as a complication. One case developed renal subcapsular hematoma which improved with conservative treatment. One case developed fever of $38^{\circ} \mathrm{C}$ or higher, which resolved with antibiotic therapy. Fifteen subjects required pentazocine for pain during the operative procedure.

Table 2 Location and size stones and number of treatment

\begin{tabular}{|c|c|c|c|c|c|c|c|c|}
\hline & & \multicolumn{6}{|c|}{$\begin{array}{c}\text { Number of } \\
\text { treatment sessions }\end{array}$} & \multirow[t]{2}{*}{$\begin{array}{c}\text { Mean } \\
\text { (session) }\end{array}$} \\
\hline & & 1 & 2 & 3 & 4 & 6 & 10 & \\
\hline & $4.1-10.0 \mathrm{~mm}$ & 4 & 1 & & & & & 1.2 \\
\hline \multirow[t]{3}{*}{ Middle renal } & $\begin{array}{c}10.1-20.0 \\
\mathrm{~mm}\end{array}$ & 20 & 9 & 3 & 4 & & & 1.8 \\
\hline & $\geq 20.1 \mathrm{~mm}$ & 1 & 1 & 4 & 3 & 1 & 1 & 3.9 \\
\hline & $4.1-10.0 \mathrm{~mm}$ & 2 & & & & & & 1 \\
\hline \multirow[t]{3}{*}{ Lower renal } & $\begin{array}{c}10.1-20.0 \\
\mathrm{~mm}\end{array}$ & 3 & 3 & & & 1 & & 2.1 \\
\hline & $\geq 20.1 \mathrm{~mm}$ & 1 & & & & & & 1 \\
\hline & $4.1-10.0 \mathrm{~mm}$ & 66 & 9 & 2 & & & & 1.2 \\
\hline \multirow[t]{3}{*}{ Upper ureteral } & $\begin{array}{c}10.1-20.0 \\
\mathrm{~mm}\end{array}$ & 28 & 5 & 2 & & & & 1.3 \\
\hline & $\geq 20.1 \mathrm{~mm}$ & 1 & & & & & & 1 \\
\hline & $4.1-10.0 \mathrm{~mm}$ & 10 & & 1 & & & & 1.2 \\
\hline \multirow[t]{2}{*}{$\begin{array}{l}\text { Middle } \\
\text { ureteral }\end{array}$} & $\begin{array}{c}10.1-20.0 \\
\mathrm{~mm}\end{array}$ & & 1 & 1 & & 1 & & 3.6 \\
\hline & $4.1-10.0 \mathrm{~mm}$ & 1 & & & & & & 1 \\
\hline \multirow[t]{2}{*}{ Lower ureteral } & $\begin{array}{c}10.1-20.0 \\
\mathrm{~mm}\end{array}$ & 31 & & & & & & 1 \\
\hline & $\geq 20.1 \mathrm{~mm}$ & 4 & 1 & & & & & 1.2 \\
\hline Total(n) & & 172 & 30 & 13 & 7 & 3 & 1 & 1.62 \\
\hline
\end{tabular}

\section{Discussion}

Since Chaussy et al. [1] reported the application of ESWL with an HM-3 lithotriptor manufactured by Dornier Co., Ltd. in clinical practice in the $1980 \mathrm{~s}$, various models of ESWL equipment have been developed and improved. Shock wave generators have been developed, starting with the underwater spark gap type, followed by the electromagnetic conversion type and the piezoelectric element type. ESWL is now the first-line treatment for upper urinary tract stones.

Our hospital introduced the Sonolith vision (manufactured by EDAP) on March 1, 2004. This model belongs to third generation ESWL equipment. It uses electrical conduction electrodes as the shock wave generator, which generates shock waves in a highly electrical-conductive fluid. It provides accurate electrical discharge with high reproducibility, thus producing stable and constant energy. The use of a hydrophone pressure detector allows real-time display of the effective pressure of shock waves on a monitor. The generator is a shallow oval shape, and the output power can be adjusted to 100 different levels. The diameter of the shock-wave head is as large as $22 \mathrm{~cm}$, and the consumptive electrodes can be used in four to five patients. This equipment has a focal depth of $130 \mathrm{~mm}$ and a focal size of $3 \times 28 \mathrm{~mm}$. The focal point is adjusted using an X-ray C-arm.

In 226 Japanese cases with renal or ureteral stones who were treated with ESWL in our hospital, the stonefree rate was $85.4 \%$ and the efficacy rate was $88.9 \%$, showing similar results to those obtained by other researchers [2-5]. (Table 4).

With regard to lower ureteral stones, Hochreiter et al. [6] treated distal ureteral stones with the HM-3 lithotriptor manufactured by Dornier in 518 patients, and reported a stone-free rate of $97.3 \%$ and efficacy rate of 99.4\%. Park et al. [7], however, reported that the stonefree rate was $55.6 \%$ for lower ureteral stones of $10 \mathrm{~mm}$ 
Table 3 Treatment results by location

\begin{tabular}{clcccc}
\hline & & 1 month & & \multicolumn{2}{c}{ 3 months } \\
\hline Site & No of pts & Stone-free rate & Efficacy rate & Stone-free rate & Efficacy rate \\
\hline Middle renal & 52 & $53.80 \%$ & $69.20 \%$ & $71.20 \%$ & $78.80 \%$ \\
Lower renal & 10 & $20.00 \%$ & $40.00 \%$ & $60.00 \%$ & $70.00 \%$ \\
Total (renal) & 62 & $48.40 \%$ & $64.50 \%$ & $69.40 \%$ & $77.40 \%$ \\
\hline Upper ureteral & 113 & $73.50 \%$ & $83.20 \%$ & $89.40 \%$ & $92.00 \%$ \\
Middle ureteral & 14 & $64.30 \%$ & $71.40 \%$ & $100 \%$ & $100 \%$ \\
Lower ureteral & 37 & $64.90 \%$ & $75.70 \%$ & $94.60 \%$ & $94.60 \%$ \\
Total (ureteral) & 164 & $70.70 \%$ & $80.50 \%$ & $91.50 \%$ & $93.30 \%$ \\
\hline
\end{tabular}

or larger. Pardalidis et al. [8] also reported that treatment was not so effective, with a stone-free rate of $84.6 \%$. Ghalayini et al. [10] compared laser TUL with ESWL, and reported that laser TUL was significantly more effective than ESWL, with a stone-free rate of 97.5\% vs. $81.5 \%$ three months after operation. Wu et al. [11] compared holmium yttrium-aluminum-garnet (YAG) laser TUL with ESWL in patients with upper ureteral stones, and reported that there was no significant difference in the treatment effect on stones $10 \mathrm{~mm}$ or smaller, with a stone-free rate of $91.1 \%$ for TUL vs. 85.3\% for ESWL, while there was a significant difference in the treatment effect on stones $10 \mathrm{~mm}$ or larger, with a stone-free rate of $76.8 \%$ for TUL vs. $35.2 \%$ for ESWL. They stated that laser TUL was superior to ESWL for the treatment of stones $10 \mathrm{~mm}$ or larger. In our study, however, all subjects with stones $10 \mathrm{~mm}$ or larger achieved a stone-free status. This may be attributable to our new measures: we usually place patients in the contralateral prone position to potentiate the treatment effect on lower ureteral stones, in accordance with the report by Köse et al. [12], and before ultrasonography we also apply jelly in a thin layer to the skin surface and to the area on the treatment table around the spot in contact with the skin to avoid exposure to air, thereby reducing minute air bubbles generated from the skin surface and minimizing attenuation of shock waves. ESWL seems to be an effective first-line treatment also in subjects who have lower ureteral stones $10 \mathrm{~mm}$ or larger but do not wish to undergo TUL, but it is sometimes difficult to treat stones greater than $10 \mathrm{~mm}$ by
ESWL monotherapy. So, it is necessary to perform ESWL and TUL combination therapy. In contrast, these subjects with X-ray-negative stones underwent intravenous pyelography (IVP) and ureteral catheter insertion in combination with ESWL. These patients of ours had a stone-free status with only ESWL therapy.

Madbouly et al. [13] recently reported that the treatment effect of ESWL with the Lithostar Multiline performed under general anesthesia was significantly greater when shock waves were delivered at a slow rate $(60 / \mathrm{min})$ than at a rapid rate $(120 / \mathrm{min})$, with an efficacy rate of $98.7 \%$ vs. $90.0 \%$. Pace et al. [14] and Peterson et al. [15] also reported similar results. Thus, ESWL treatment should be performed at a slow rate in the future.

Complications of ESWL include renal subcapsular hematoma, the incidence of which has been reported to be between $0.078 \%$ and $0.6 \%[1,16]$, and has also been reported to increase up to $32 \%$ as a result of performance of postoperative routine CT and MRI [17]. Risk factors for renal subcapsular hematoma are reported to be 1) hypertension, 2) coagulopathy, and 3) previous ESWL therapy [18]. In our study, renal subcapsular hematoma occurred in one subject. This subject had a history of hypertension, which may have caused this complication.

\section{Conclusions}

ESWL with the Sonolith vision manufactured by EDAP produced a treatment effect equivalent to those achieved with other models of ESWL equipment. ESWL seems to be an effective first-line treatment also in patients who

Table 4 Treatment results by model

\begin{tabular}{cccccc}
\hline & White et al. & Johnson et al. & Egilmez et al & Nomikos et al. & Our institute \\
\hline Manufacturer & Dornier & Dornier & Siemens & EDAP & EDAP \\
Model & Delta lithotriptor & Delta S lithotriptor & Lithostar & Sonolith vision & Sonolith vision \\
No. of cases & 5735 & 270 & 2670 & 309 & 226 \\
Location of Stone & kidney/ureter & kidney/ureter & kidney/ureter & kidney & kidney/ureter \\
Stone-free rate (\%) & 58.5 & 73.3 & 79 & 75 & 85.4 \\
Eficacy rate (\%) & 85.1 & 85.6 & & 88.9 \\
\hline
\end{tabular}


have lower ureteral stones $10 \mathrm{~mm}$ or larger but do not wish to undergo TUL, if measures such as suitable positioning of patients during treatment are taken.

\section{Acknowledgements}

Written consent was obtained from the patient and his family prior to publication of this manuscript.

\section{Author details}

'Department of Urology, Aichi Medical University School of Medicine Nagakute, Aichi 480-1195, Japan. ${ }^{2}$ Department of Urology, Meitetsu Hospital Nagoya, Aichi 451-8511, Japan.

\section{Authors' contributions}

KN and MT drafted the report, cared for the patient and approved the final version of the manuscript. MN, TY, GN, YK, RK, KZ, SA, YY and NH cared for the patient and approved the final version of the manuscript. MS approved the final version of the manuscript.

\section{Competing interests}

The authors declare that they have no competing interests.

Received: 5 April 2011 Accepted: 12 December 2011

Published: 12 December 2011

\section{References}

1. Chaussy C, Schuller J, Schmiedt E, Brandl H, Jocham D, Liedl B: Extracorporeal shock-wave lithotripsy (ESWL) for treatment of urolithiasis. Urology 1984, 23:59-66.

2. White W, Klen F: Five-year clinical experience with the Dornier Delta lithotripter. Urology 2006, 68:28-32.

3. Johnson DB, Lowry PS, Schluckebier JA, Kryger JV, Nakada SY: University of Wisconsin experience using the Doli S lithotripter. Urology 2003, 62:410-415.

4. Egilmez T, Tekin MI, Gonen M, Kilinc F, Goren R, Ozkardes H: Efficacy and safety of a new-generation shockwave lithotripsy machine in the treatment of single renal or ureteral stones: Experience with 2670 patients. J Endourol 2007, 21:23-27.

5. Nomikos MS, Sowter SJ, Tolley DA: Outcomes using a fourth-generation lithotripter: a new benchmark for comparison. BJU Int 2007, 100:1356-1360.

6. Hochreiter WW, Danuser H, Perrig M, Studer UE: Extracorporeal shock wave lithotripsy for distal ureteral calculi: What a powerful machine can achieve. J Urol 2007, 169:878-880.

7. Park H, Park M, Park T: Two-year experience with ureteral stones: Extracorporeal shockwave lithotripsy $\mathrm{v}$ ureteroscopic manipulation. $J$ Endourol 1998, 12:501-504.

8. Pardalidis NP, Kosmaoglou EV, Kapotis CG: Endoscopy vs. extracorporeal shockwave lithotripsy in the treatment of distal ureteral stone: ten years' experience. J Endourol 1999, 13:161-164.

9. Pearle MS, Nadler R, Bercowsky E, Chen C, Dunn M, Figenshau RS, Hoenig DM, MCDougall EM, Mutz J, Nakada SY, Shalhav AL, Sundaram C, Wolf JS Jr, Clayman RV: Prospective randomized trial comparing shock wave lithotripsy and ureterosopy for management of distal ureteral calculi. J Urol 2001, 166:1255-1260.

10. Ghalayini IF, Al-Ghazo MA, khader YS: Extracorporeal shockwave lithotripsy versus ureteroscopy for distal ureteric calculi: Efficacy and patient satisfaction. Int Braz J Urol 2006, 32:656-664.

11. Wu CF, Chen CS, Lin WY, Shee JJ, Chen Y, Huang WS: Therapeutic options for proximal ureter stone: Extracorporeal shock wave lithotripsy versus semirigid ureterorenoscope with Holmium: Yttrium-aluminum-garnet laser lithotripsy. Urology 2005, 65:1075-1079.

12. Köse AC, Demirbas M: The modified prone position: a new approach for treating prevesical stones with extracorporeal shock wave lithotripsy. BJU Int 2004, 93:369-373.

13. Madbouly K, El-Tiraifi AM, Seida M, El-Fagih SR, Atassi R, Talic RF: Slow versus fast shock wave lithotripsy rate for urolithiasis: A prospective randomized study. J Urol 2005, 173:127-130.
14. Pace KT, Ghiculete D, Harju M: Shock wave lithotripsy at 60 or 120 shocks per minute: A randomized, double-blind trial. J Urol 2005, 174:595-599.

15. Paterson RF, Lifshitz DA, Lingeman JE, Evan AP, Connors BA, Fineberg NS, Williams JC Jr, MCAteer JA: Stones fragmentation during shock wave lithotripsy is improved by slowing the shock wave rate: Study with a new animal model. J Urol 2002, 168:2211-2215.

16. Newman LH, Saltzman B: Identifying risk factors in development of clinically significant post-shock-wave lithotripsy subcapsular hematomas. Urology 1991, 38:35-38.

17. Knapp PM, Kulb TB, Lingeman JE, Newman DM, Mertz JH, Mosbaugh PG, Steele RE: Extra corporeal shock wave lithotripsy-induced perirenal hematomas. J Urol 1998, 139:700-703.

18. Collado Serra A, Huguet Pérez J, Monreal García de Vicuńa F, Rousaud Barón A, Izquierdo de la Torre F, Vicente Rodríquez J: Renal hematoma as a complication of extracorporeal shock wave lithotripsy. Scand J Urol Nephrol 1999, 33:171-175.

Pre-publication history

The pre-publication history for this paper can be accessed here: http://www.biomedcentral.com/1471-2490/11/26/prepub

doi:10.1186/1471-2490-11-26

Cite this article as: Nakamura et al.: Treatment of upper urinary tract stones with extracorporeal shock wave lithotripsy (ESWL) Sonolith vision. BMC Urology 2011 11:26.

\section{Submit your next manuscript to BioMed Central and take full advantage of:}

- Convenient online submission

- Thorough peer review

- No space constraints or color figure charges

- Immediate publication on acceptance

- Inclusion in PubMed, CAS, Scopus and Google Scholar

- Research which is freely available for redistribution 